\title{
Efferent Feedback Slows Cochlear Aging
}

\author{
M. Charles Liberman, ${ }^{1,2,3}$ Leslie D. Liberman, ${ }^{2}$ and Stéphane F. Maison ${ }^{1,2,3}$ \\ ${ }^{1}$ Department of Otology and Laryngology, Harvard Medical School, Boston, Massachusetts $02114,{ }^{2}$ Eaton-Peabody Laboratory, Massachusetts Eye and Ear \\ Infirmary, Boston, Massachusetts 02114-3096, and ${ }^{3}$ Harvard Program in Speech and Hearing Bioscience and Technology, Boston, Massachusetts 02114
}

The inner ear receives two types of efferent feedback from the brainstem: one pathway provides gain control on outer hair cells' contribution to cochlear amplification, and the other modulates the excitability of the cochlear nerve. Although efferent feedback can protect hair cells from acoustic injury and thereby minimize noise-induced permanent threshold shifts, most prior studies focused on highintensity exposures ( $>100 \mathrm{~dB}$ SPL). Here, we show that efferents are essential for long-term maintenance of cochlear function in mice aged 1 year post-de-efferentation without purposeful acoustic overexposure. Cochlear de-efferentation was achieved by surgical lesion of efferent pathways in the brainstem and was assessed by quantitative analysis of immunostained efferent terminals in outer and inner hair cell areas. The resultant loss of efferent feedback accelerated the age-related amplitude reduction in cochlear neural responses, as seen in auditory brainstem responses, and increased the loss of synapses between hair cells and the terminals of cochlear nerve fibers, as seen in confocal analysis of the organ of Corti immunostained for presynaptic and postsynaptic markers. This type of neuropathy, also seen after moderate noise exposure, has been termed "hidden hearing loss", because it does not affect thresholds, but can be seen in the suprathreshold amplitudes of cochlear neural responses, and likely causes problems with hearing in a noisy environment, a classic symptom of age-related hearing loss in humans. Since efferent reflex strength varies among individuals and can be measured noninvasively, a weak reflex may be an important risk factor, and prognostic indicator, for age-related hearing impairment.

Key words: auditory neuropathy; feedback; hair cells; hearing conservation

\section{Introduction}

The inner ear has an enormous dynamic range: sounds at pain threshold (140 dB SPL) are 10 million times greater in amplitude than at the threshold of hearing ( $0 \mathrm{~dB}$ SPL). Exposures $>100 \mathrm{~dB}$ SPL, although not painful, can damage cochlear sensory cells in as little as $1 \mathrm{~h}$ (Robertson et al., 1980; Bohne and Rabbitt, 1983). The resultant hearing loss can be permanent (Liberman and Dodds, 1984), since hair cells do not regenerate in mammals (Rubel et al., 2013).

Olivocochlear neurons, the effectors of the inner ear's sound-evoked efferent reflex, comprise a negative-feedback gain-control system (Wiederhold and Kiang, 1970) that can reduce noise-induced cochlear damage (Rajan, 1988). At moderate and high sound levels, sound-evoked efferent feedback to outer hair cells reduces their normal amplification of sound-induced cochlear motion (Murugasu and Russell, 1996). Despite evidence showing that de-efferentation renders the cochlea more vulnerable to acoustic injury (Kujawa and Liberman, 1997), the evolutionary significance of efferent-mediated protection has been questioned. Since natural environments do not typically contain traumatic sound levels (Christopher Kirk and Smith, 2003), the

Received Nov. 23, 2013; revised Feb. 15, 2014; accepted Feb. 22, 2014.

Author contributions: M.C.L. and S.F.M. designed research; L.D.L. and S.F.M. performed research; M.C.L. and S.F.M. analyzed data; M.C.L. and S.F.M. wrote the paper.

Research was supported by National Institute on Deafness and Other Communication Disorders Grants R01 DC 0188 and P30 DC 05209.

Correspondence should be addressed to Dr. Stéphane F. Maison, Eaton-Peabody Laboratory, Massachusetts Eye and Ear Infirmary, 243 Charles Street, Boston, MA 02114-3096. E-mail: stephane_maison@meei.harvard.edu.

DOI:10.1523/JNEUROSCI.4923-13.2014

Copyright $\odot 2014$ the authors $\quad 0270-6474 / 14 / 344599-09 \$ 15.00 / 0$ selective pressure to evolve hair cell protection appears to have been lacking until recently.

Recent work has revealed that moderate exposures (80-100 $\mathrm{dB}$ ), causing only transient threshold elevation, can cause degeneration of cochlear sensory neurons, without loss of hair cells (Kujawa and Liberman, 2009; Maison et al., 2013). This primary neuronal degeneration appears, within hours post-exposure, as a loss of synaptic terminals on inner hair cells (Robertson, 1983), likely from glutamate excitotoxicity (Pujol and Puel, 1999). Death of the neuronal somata, the spiral ganglion cells, is much slower, continuing for months to years post-exposure (Liberman and Kiang, 1978). Thresholds can recover, because the neuropathy is selective for the subset of cochlear nerve fibers with high thresholds (Furman et al., 2013). These high-threshold fibers are important for hearing in noise, since their lack of sensitivity prevents them from being driven to saturation by ongoing background sounds (Costalupes et al., 1984).

This type of "hidden hearing loss" (Schaette and McAlpine, 2011) is likely important in presbycusis, i.e., the hearing impairment of old age (Dubno et al., 1984). Aging people experience increasing difficulties hearing in noise, and the aging cochlea can show significant neural degeneration well before loss of hair cells (Makary et al., 2011). If age-related cochlear neuropathy is caused by cumulative exposure to everyday "nontraumatic" sound, then feedback from the cochlea's cholinergic efferent neurons might minimize it, and therefore slow the progression of age-related hearing loss.

The present experiment was designed to assess olivocochlear contributions to cochlear nerve protection in the aging ear. Results show that surgical de-efferentation accelerates the loss of 


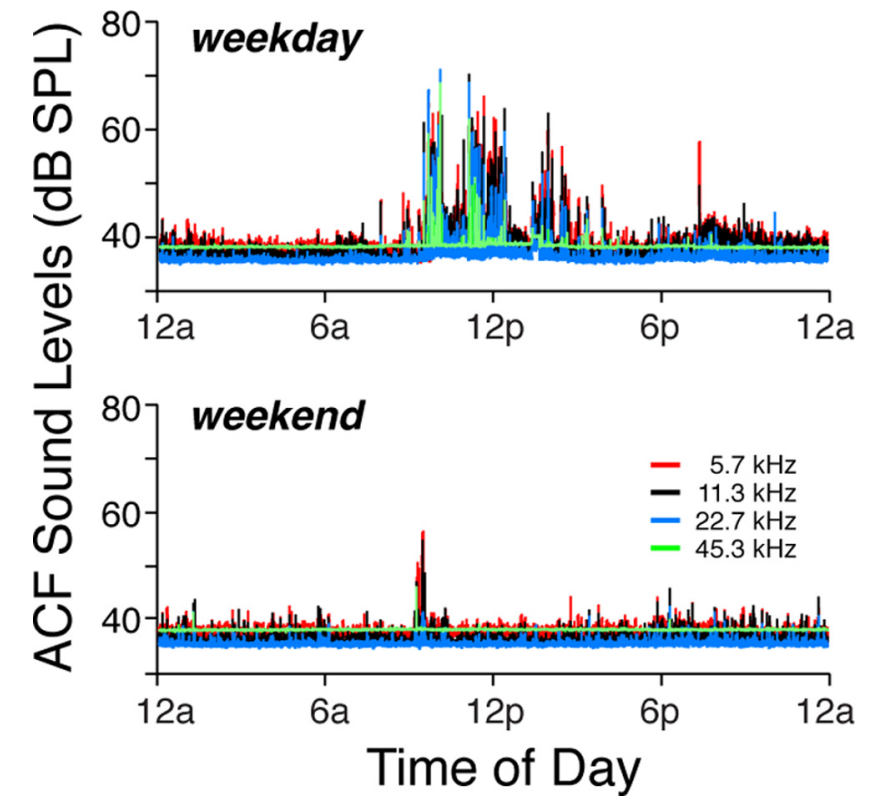

Figure 1. Sound levels in the Animal Care Facility. Ambient sound pressure levels over one $24 \mathrm{~h}$ period on a weekday or a weekend, as indicated in the panel. Levels were measured in half-octave bands, as shown in the key. Each sample was $100 \mathrm{~ms}$ in duration.

cochlear nerve synapses in mice aged without acoustic overexposure. The protective effects are apparently mediated both by medial olivocochlear (MOC) neurons, projecting to outer hair cells, and lateral olivocochlear (LOC) neurons, which innervate the dendrites of cochlear-nerve fibers near their synapses with inner hair cells, and which have been implicated in the control of glutamate excitotoxicity (Pujol and Puel, 1999).

\section{Materials and Methods}

Animals, groups, statistics and environmental noise. Male mice (CBA/CaJ strain) entered the experimental protocol at 6 weeks of age and were assigned to one of three groups: (1) Control animals, which underwent no surgical procedure ( $n=20$ ears; histology was performed only on a subset of 6 ears); (2) Midline Cut animals ( $n=48$ ears from 24 animals), in which the crossed olivocochlear (OC) bundle was surgically transected; and (3) LSO Injection animals ( $n=20$ ears from 20 animals), in which a neurotoxin (melittin) was stereotaxically injected to target the lateral superior olive (LSO) on the right side (Maison et al., 2013). After surgery, lesioned and control mice were returned to the animal care facility. For each animal in each group, cochlear function was assessed bilaterally via auditory brainstem responses (ABRs) and distortion product otoacoustic emissions (DPOAEs) at 8, 11, 16, 22, 32, and 45 weeks of age. Immediately after the final cochlear function test, cochleas were fixed by intracardiac perfusion and removed for histological processing and subsequent confocal analysis of hair cell and synaptic degeneration. In one additional Control group ( $n=6$ ears), ears were extracted for histological processing at 8 weeks of age. Statistical significance of the intergroup differences was assessed by $t$ test. All procedures were approved by the Institutional Animal Care and Use Committee of the Massachusetts Eye and Ear Infirmary.

Ambient sound pressure levels in the animal care facility were recorded by placing a tiny electret microphone (Knowles FG-23329-PO7) in an empty mouse cage within the same rack, in the same room, where the mice were housed for the duration of the experiment, during which time the position of the rack within the room was not changed by more than a few feet. Acoustic signals were measured continuously for $48 \mathrm{~h}$ on four separate occasions: twice during the week and twice over the weekend. Data from one weekday and one weekend day are shown in Figure 1. When animal-care personnel were not in the room, sound pressure levels, analyzed in half-octave bands and at $100 \mathrm{~ms}$ intervals, were $<40 \mathrm{~dB}$
SPL throughout the range of mouse hearing, i.e., from 4 to $64 \mathrm{kHz}$. Peak noise levels occurred during cage cleaning and daily maintenance and never exceeded $70 \mathrm{~dB}$ SPL. They tended to be higher on weekdays than on the weekend.

Cochlear function tests. For measuring cochlear function via ABRs and DPOAEs, animals were anesthetized with xylazine $(20 \mathrm{mg} / \mathrm{kg}$, i.p. $)$ and ketamine $(100 \mathrm{mg} / \mathrm{kg}$, i.p.) and placed in an acoustically electrically shielded room maintained at $32^{\circ} \mathrm{C}$. Acoustic stimuli were delivered through a custom acoustic system consisting of two miniature dynamic earphones used as sound sources (CUI CDMG15008-03A) and an electret condenser microphone (Knowles FG-23329-PO7) coupled to a probe tube to measure sound pressure near the eardrum (for details see http://www.masseyeandear.org/research/ent/eaton-peabody/ epl-engineering-resources/epl-acoustic-system/).

Digital stimulus generation and response processing were handled by digital I-O boards from National Instruments driven by custom LabVIEW software. For ABRs, stimuli were $5 \mathrm{~ms}$ tone pips $\left(0.5 \mathrm{~ms} \cos ^{2}\right.$ rise-fall) delivered in alternating polarity at $35 / \mathrm{s}$. Electrical responses were sampled via Grass needle electrodes at the vertex and pinna with a ground reference near the tail and amplified $10,000 \times$ with a $0.3-3 \mathrm{kHz}$ passband. Responses to as many as 1024 stimuli were averaged at each sound pressure level, as level was varied in $5 \mathrm{~dB}$ steps from below threshold up to $80 \mathrm{~dB}$ SPL. For DPOAEs, stimuli were two primary tones $f_{1}$ and $f_{2}\left(f_{2} / f_{1}=1.2\right)$, with $f_{1}$ level always $10 \mathrm{~dB}$ above $f_{2}$ level. Primaries were swept in $5 \mathrm{~dB}$ steps from 20 to $80 \mathrm{~dB} \mathrm{SPL}$ ( for $f_{2}$ ). The DPOAE at $2 f_{1}-f_{2}$ was extracted from the ear canal sound pressure after both waveform and spectral averaging. Noise floor was defined as the average of 6 spectral points below, and 6 above, the $2 f_{1}-f_{2}$ point. Threshold was computed by interpolation as the primary level $\left(f_{2}\right)$ required to produce a DPOAE of 0 dB SPL.

Olivocochlear function tests. After anesthetization with urethane (1.20 $\mathrm{g} / \mathrm{kg}$, i.p.) and xylazine $(20 \mathrm{mg} / \mathrm{kg}$, i.p.), the mouse was connected to a respirator via a tracheal cannula. A posterior craniotomy and partial cerebellar aspiration exposed the floor of the IV ${ }^{\text {th }}$ ventricle. To stimulate the olivocochlear bundle, shocks (monophasic pulses, $150 \mu$ s duration, $200 / \mathrm{s}$ ) were applied through fine silver wires (0.4 mm spacing) placed along the midline, spanning the olivocochlear decussation. Shock threshold for facial twitches was determined, and muscle paralysis was induced with $\alpha$-D-tubocurarine ( $1.25 \mathrm{mg} / \mathrm{kg}$, i.p.). Shock levels were then raised to $6 \mathrm{~dB}$ above twitch threshold. During the olivocochlear suppression assay, $f_{2}$ level was set to produce a DPOAE $10-15 \mathrm{~dB}$ above the noise floor, which ranged from -15 to $-8 \mathrm{~dB}$ depending on DPOAE frequency. To measure olivocochlear effects, repeated measures of baseline DPOAE amplitude were first obtained $(n=54)$, followed by a series of 70 contiguous periods in which DPOAE amplitudes were measured with simultaneous shocks to the olivocochlear bundle and additional periods during which DPOAE measures continued after the termination of the shock train. During paralysis, heart rate was monitored, and urethane boosters were administered every hour at $25 \%$ of the initial dose (Maison et al. 2007).

Brainstem lesions and histological verification. For brainstem surgery, mice were anesthetized with xylazine $(20 \mathrm{mg} / \mathrm{kg}$, i.p.) and ketamine $(100$ $\mathrm{mg} / \mathrm{kg}$, i.p.). Midline cuts were made with a microknife on the floor of the $\mathrm{IV}^{\text {th }}$ ventricle after a posterior craniotomy and cerebellar elevation. For lesions of the LSO, the mouse was held in a stereotaxic apparatus with the scalp retracted. A micropipette filled with $10 \mathrm{~mm}$ melittin was lowered into the brain, through an opening over the right lambdoidal suture, at a position $0.49 \mathrm{~cm}$ caudal and $0.12 \mathrm{~cm}$ lateral to bregma. At a depth of 0.69 $\mathrm{cm}, 0.2 \mu \mathrm{l}$ of melittin was injected by a $1 \mu \mathrm{l}$ Hamilton syringe. Brainstems were fixed in $4 \%$ paraformaldehyde, cryoprotected ( $30 \%$ sucrose), and cut on a freezing microtome at $40 \mu \mathrm{m}$ in the transverse plane. Sections were treated histochemically to reveal acetylcholinesterase activity (Osen and Roth, 1969).

Cochlear processing, immunostaining, and histological analysis. Mice were perfused intracardially with $4 \%$ paraformaldehyde in phosphate buffer. Cochleas were decalcified, dissected into half-turns, and permeabilized by freeze/thawing. The half-turns were blocked in $5 \%$ normal horse serum (NHS) with 1\% Triton X-100 (TX) in PBS for $1 \mathrm{~h}$, followed by incubation for $\sim 19 \mathrm{~h}$ at $37^{\circ} \mathrm{C}$ in primary antibodies diluted in $1 \%$ 
A

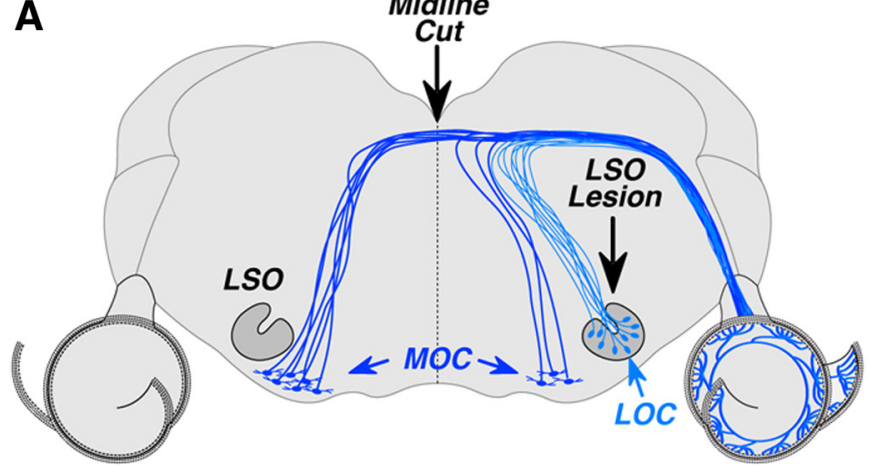

Control
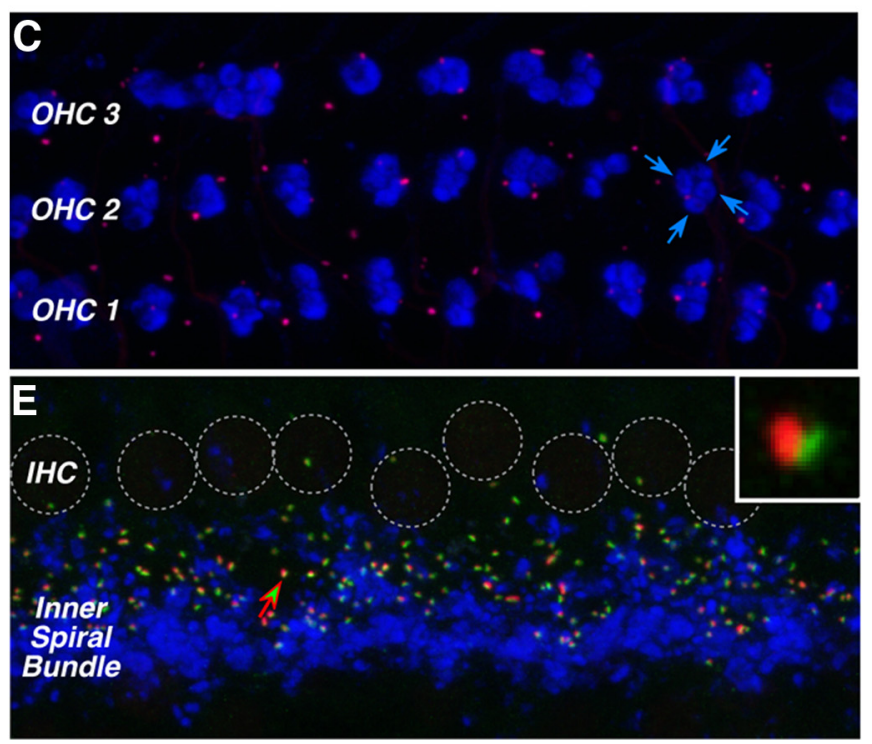

B

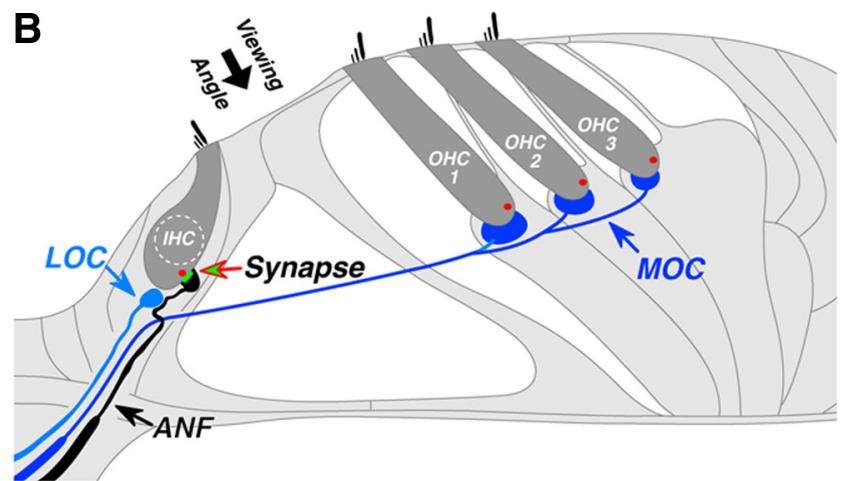

De-efferented

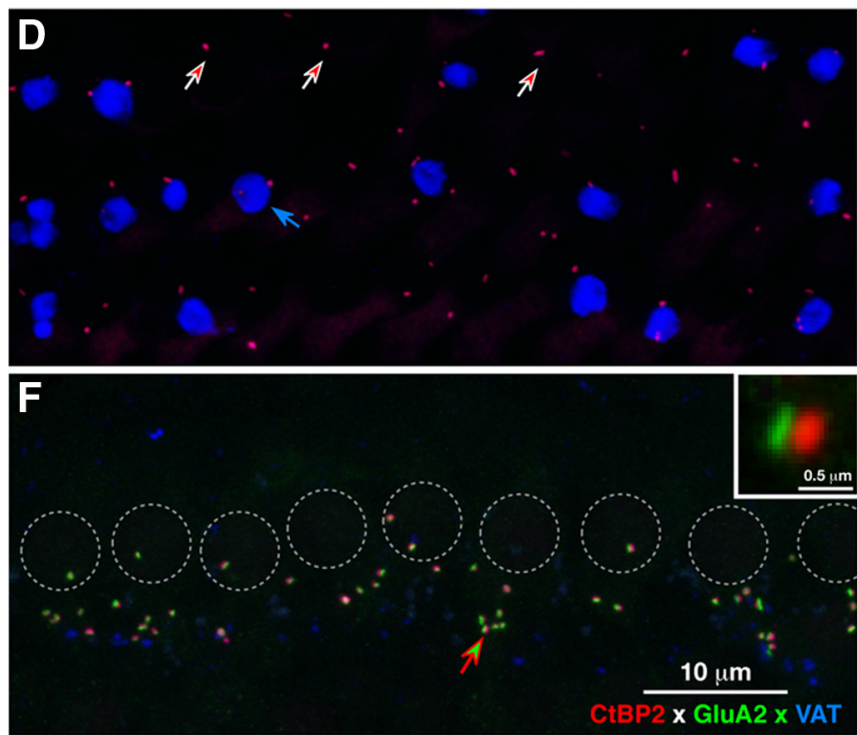

Figure 2. Immunostaining of the cochlear efferent and afferent innervation in normal and de-efferented cases. $A$, Brainstem schematic shows the central origins of $L O C$ and $M O C$ efferents. Efferent pathways were lesioned via midline cut of MOC fibers at the floor of the IV ${ }^{\text {th }}$ ventricle or by neurotoxin injection into the LSO where LOC fibers originate. $B$, Organ of Corti schematic shows the peripheral targets of cochlear efferents. MOC terminals synapse with outer hair cells (OHCs); $\mathrm{LOC}$ terminals synapse with auditory nerve fibers (ANFs) near their afferent synapses with the inner hair cell (IHC). Each IHC-ANF synapse is identifiable by its presynaptic ribbon (red) and postsynaptic glutamate receptors (green). The small population of cochlear nerve fibers ( $<5 \%$ ) that contact $\mathrm{OHCS}$ are not shown. $\mathbf{C}-\boldsymbol{F}$, The success of de-efferentation was assessed by immunostaining cochlear efferent terminals with antibodies for VAT (blue); IHC-ANF synapses were stained for a protein in the presynaptic ribbon (CtBP2; red) and an AMPA postsynaptic glutamate receptor (GluA2; green). Each image is a maximum projection of a focal series through the synaptic region of the $0 \mathrm{HCS}$ $(\boldsymbol{C}, \boldsymbol{D})$ or IHCS $(\boldsymbol{E}, \boldsymbol{F})$, from the viewing angle schematized in $\boldsymbol{B}$. Each control $\mathrm{OHC}(\boldsymbol{C})$ is innervated by a cluster of $1-4 \mathrm{MOC}$ terminals (e.g., blue arrows); in the de-efferented ear (D), many $0 \mathrm{OHC}(\mathrm{s}$ have no MOC endings, but presynaptic ribbons remain near the ANF terminals (e.g., at arrows). In the IHC area $(\boldsymbol{E}, \boldsymbol{F})$, individual sensory cells are difficult to distinguish, so their nuclei are indicated by dashed circles. In the control ear $(\boldsymbol{E})$, cochlear nerve synapses are seen as paired red-green puncta in the subnuclear zone, just above the LOC terminals in the inner spiral bundle. In the de-efferented $\operatorname{ear}(\boldsymbol{F})$, synaptic counts are reduced, and the LOC innervation is almost completely eliminated. In each IHC panel, one synapse (at the arrow) is shown at higher magnification in the inset. Scale bar in $\boldsymbol{F}$ applies to all large images. Scale bar in one inset applies to both. All images are from the middle of the cochlear spiral ( $16 \mathrm{kHz})$. $\boldsymbol{D}$ is from a midline-cut case; $\boldsymbol{F}$ is from an $\mathrm{LSO}$ lesion case.

NHS with 1\% TX. Antibodies included (1) mouse (IgG1) anti-CtBP2 from BD Biosciences at 1:200 and (2) rabbit anti-VAT (vesicular acetylcholine transporter) from Sigma at 1:1000 to allow quantification of presynaptic ribbons in inner hair cells and cochlear efferent terminals, respectively. To quantify postsynaptic elements in the inner hair cell area, we used mouse (IgG2a) anti-GluA2, from Millipore, at 1:2000. Primary incubations were followed by two sequential $60 \mathrm{~min}$ incubations at $37^{\circ} \mathrm{C}$ in species- and isotype-appropriate secondary antibodies with $1 \%$ TX.

Three types of information were extracted from both inner and outer hair cell areas in each cochlea: (1) counts of afferent synapses, (2) quantification of the degree of de-efferentation, and (3) counts of inner and outer hair cells. All three types of analyses were based on high-power confocal $z$-stacks obtained at half-octave intervals along the cochlear spiral from 5.6 to $64 \mathrm{kHz}$. To accurately identify regions of interest, cochlear lengths were obtained for each case by tracing the cochlear spiral in low-power images of the dissected epithelial whole mounts using a custom ImageJ plugin (http://www.masseyeandear.org/research/ent/ eaton-peabody/epl-histology-resources/) that translates cochlear position into frequency according to the published map for the mouse
(Taberner and Liberman, 2005). Confocal $z$-stacks were obtained with a glycerol-immersion objective $(63 \times$, numerical aperture $=1.3)$ at $3.17 \times$ digital zoom on a Leica TCS SP5. Image spacing in the $z$ plane was set to $0.25 \mu \mathrm{m}$, and the $z$-span was carefully adjusted for each stack to include all synaptic elements in all of the 9-12 hair cells from each row included in each stack, typically requiring $75-100$ images per stack. Two adjacent stacks were always obtained in each cochlear region sampled.

Presynaptic ribbons and postsynaptic glutamate receptor patches were counted from each confocal $z$-stack using the connected components tool in Amira software (Visage Imaging), which finds and displays each voxel space in an image stack containing exclusively pixel values greater than a user-set criterion. By comparing the "connected components" display to the maximum projection, the user can adjust the criterion to capture all the elements of interest; because the analysis is done in $3 \mathrm{D}$, the result accurately separates elements superimposed in $z$. To quantitatively assess the pairing of presynaptic and postsynaptic elements, we use custom software that extracts the voxel space within $1 \mu \mathrm{m}$ around each ribbon (or receptor patch) and produces a thumbnail array of these miniature projections, that can be scanned to count synapses (i.e., rib- 
bons with closely apposed receptor patches) versus orphan ribbons or orphan receptor patches (Liberman et al., 2011). Hair cells in each stack were counted by increasing the image output-gain (gamma adjust): inner hair cell nuclei stain faintly with the CtBP2 antibody, and the outer hair cell somata are visible via their faint background label in several confocal channels, as well as by the presence of synaptic ribbons, even when the efferent terminals are missing.

The degree of de-efferentation was assessed in both inner and outer hair cell areas from maximum projections of the VAT-immunostaining in the $z$-stacks. In the outer hair cell area, the total number of VAT-positive terminals was counted in each stack and divided by the number of hair cells $(\sim 10$ outer hair cells in each of the three rows). In the inner hair cell area, counting efferent terminals is difficult because they are smaller, more numerous, and overlap with each other in the $x y$ projections. Thus, the LOC innervation was quantified by measuring the projected $2 \mathrm{D}$ area of the terminals using the auto-thresholding algorithm from ImageJ on the VAT channel from the maximum projections.

\section{Results}

Assessing cochlear de-efferentation via cholinergic immunostaining

To assess the contribution of olivocochlear efferents to cochlear nerve survival in the aging ear, we lesioned the efferent pathways in young (6 week) mice, either by injecting a neurotoxin into the brainstem where the LOC fibers originate, or by cutting the MOC fibers where they cross the brainstem midline at the floor of the $\mathrm{IV}^{\text {th }}$ ventricle (Fig. 2A). Based on published reports of the innervation patterns in mouse (Brown, 1993; Maison et al., 2003), a midline cut should remove approximately two-thirds of the MOC projections to both ears. If the cut is off midline, it will begin to impinge on some of the axons of ipsilaterally projecting MOC and LOC cells. A complete LSO lesion should remove virtually all the LOC projections to the ipsilateral ear without affecting the MOC system. However, if the neurotoxin spreads medially, the lesion will also involve ipsilateral MOC projections.

The success of de-efferentation was assessed, 39 weeks later, by histological evaluation of sectioned brainstems and cochlear epithelial whole mounts, using cholinergic markers to visualize efferent cells of origin and their peripheral projections, respectively (Maison et al., 2003). Brainstem sections were evaluated qualitatively to identify cases where the lesion missed the target. Cochlear tissue was immunostained to assess the extent of deefferentation more quantitatively, and as a function of cochlear location.

In control ears, immunostaining for VAT (blue) shows MOC and LOC terminals in the outer and inner hair cell areas (Fig. $2 C, E$, respectively). As seen in the confocal image stack in Figure $2 C$, each outer hair cell, in each of the three rows, is normally contacted by a cluster of VAT-positive MOC terminals at its ba-
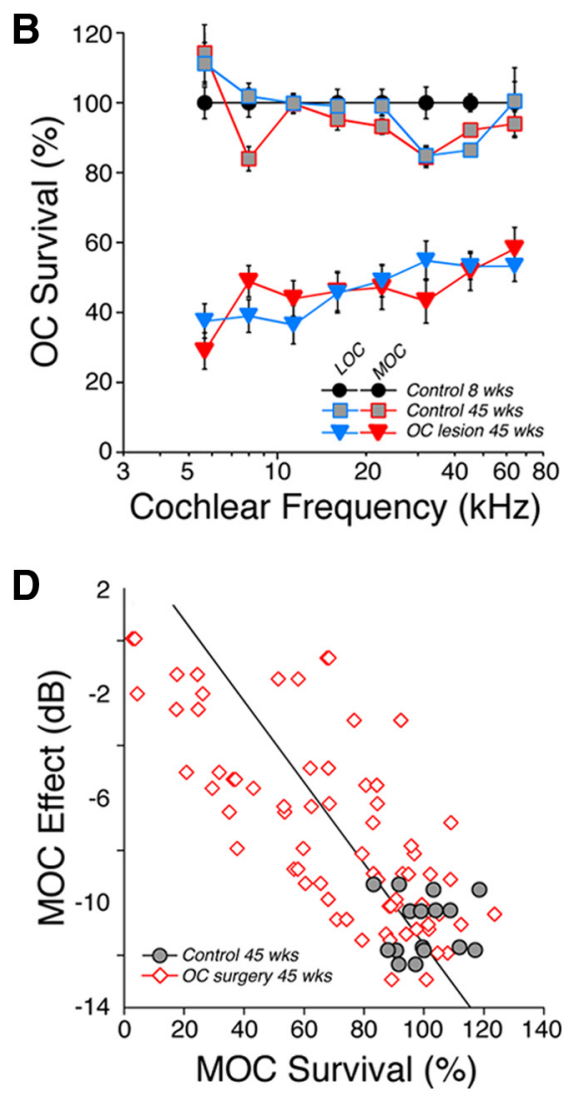

Figure 3. Histological and physiological assessment of the degree of de-efferentation. $A$, Mean survival of MOC vS $L O C$ terminals at 45 weeks of age. For each ear, confocal image stacks (e.g., Fig. 1C $-F$ ) were obtained from 8 cochlear locations ). MOC and LOC innervation was quantified in each stack as described in Materials and Methods and then averaged expressed as "survival" by normalizing to regional mean values for young ( 8 week) Controls $(n=6)$. Cochlear regions with $<75 \%$ survival of both LOC and MOC terminals (dashed lines) were classified as OC Lesion ( $n=44$ surgical cases). Each region from each case generates one point in $\boldsymbol{A}$ and was considered independently for this and all subsequent analyses. $\boldsymbol{B}$ The degree of de-efferentation in $O C$ Lesion regions was relatively uniform throughout the cochlear spiral. Group mean data significant at all frequencies ( $p \ll 0.001$ ). C, To measure MOC effects in vivo, DPOAEs were measured before, during, and strain of shocks to the 0 C bundle (gray box). Response amplitudes are normalized to preshock values, and the size frequency $\left(f_{2}\right)$ for 0 C Lesion regions (defined in $A$ ) compared with control $(n=14)$. Intergroup differences were significant at the $p \ll 0.01$ level for test frequencies at 11.3, 16, 22.6 and $45.2 \mathrm{kHz}$. D. The size of the MOC effect in individual cases, shown here for $f_{2}=22.6 \mathrm{kHz}$, correlates $(r=0.76)$ with survival of MOC innervation in the appropriate cochlear region of the same ear. For $\boldsymbol{D}$, data are shown from controls and all surgical cases where DPOAEs were robust enough to record shock-evoked MOC effects $(n=41)$.

solateral pole (Fig. $2 B$ ). In the inner hair cell area, VAT-positive LOC terminals are smaller and more diffusely organized within the inner spiral bundle, which runs near the basolateral poles of the inner hair cells, where they make synaptic contact primarily with the dendrites of cochlear nerve terminals near their synapses with the inner hair cell (Fig. 2B).

Our brainstem lesions (Fig. $2 A$ ) sometimes produced virtually complete de-efferentation, as seen in the inner hair cell area shown in Figure $2 F$, where essentially no LOC terminals remain. However, in most cases, the de-efferentation was subtotal, as illustrated for the outer hair cell area in Figure 2D, where 17 of the 33 outer hair cells have MOC terminal clusters, and where the number of terminals per cluster is reduced among the cells that remain innervated. The de-efferented hair cells remain intact, as suggested by the presence of synaptic ribbons (Fig. 2D, arrows) and as can be verified by examination of these epithelial whole mounts with DIC optics (data not shown). 

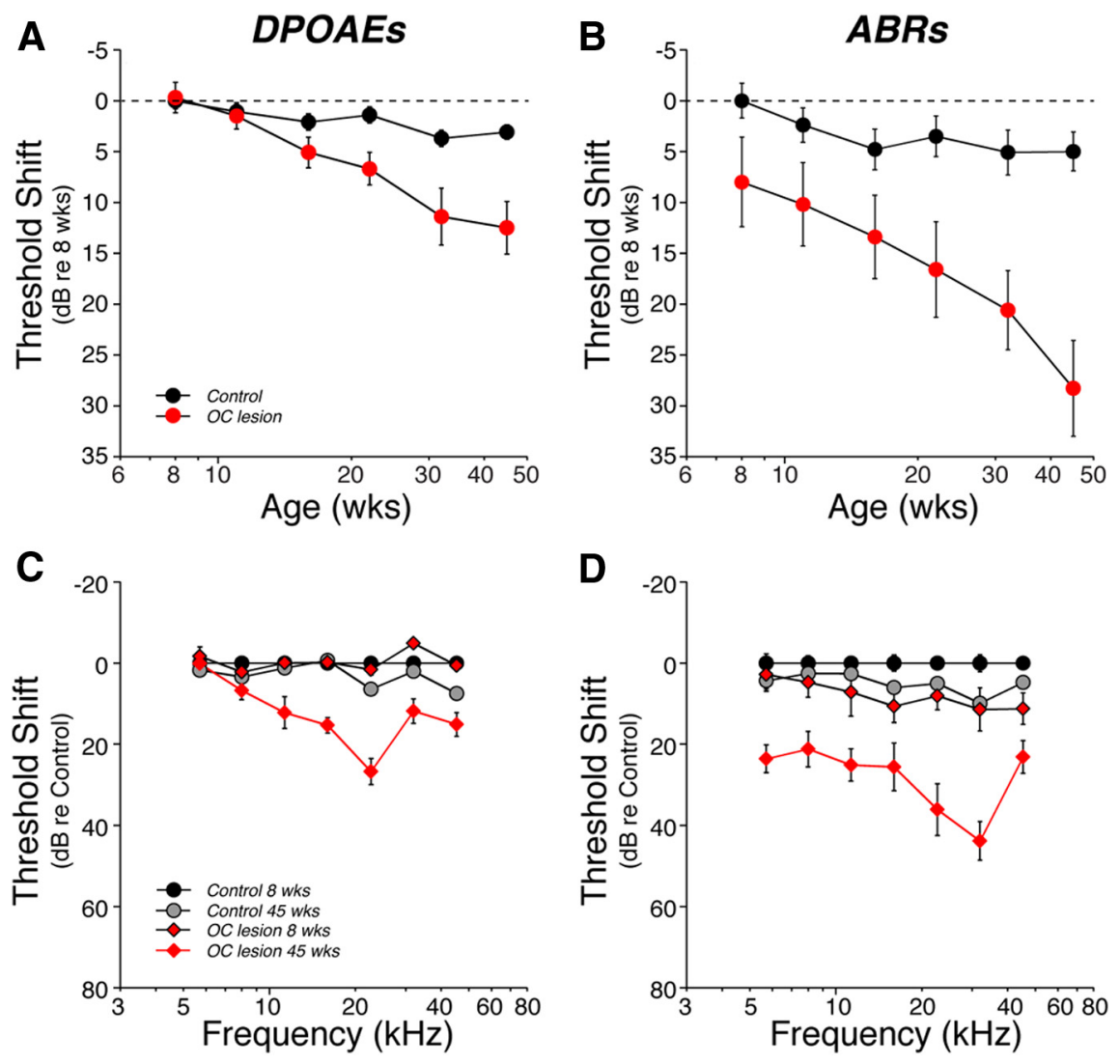

Figure 4. Age-related threshold shift was more pronounced in de-efferented regions, especially as measured via $A B R s . A, B$, Mean threshold shift ( \pm SEM) vs age for Control vs OC Lesion groups, as seen via DPOAEs $(\boldsymbol{A})$ or ABRs $(\boldsymbol{B})$. Data from each group are averaged across all test frequencies. $\boldsymbol{C}, \boldsymbol{D}$, Mean cochlear threshold shift ( $\pm S E M$ ) vs frequency for Control vs $0 C$ Lesion groups as seen via DPOAEs $(\boldsymbol{C}$ or ABRs $(\boldsymbol{D})$. For DPOAEs, differences between the $0 \mathrm{C}$ Lesion group at 45 weeks and age-matched controls were significant at the $p \ll 0.01$ level for $11.3,16,22.6$, and $32 \mathrm{kHz}$; differences at $45.2 \mathrm{kHz}$ were significant at the $p<0.05$ level. For ABRs, differences were significant at the $p<0.01$ level for $5.6,8,22.6$, and $32 \mathrm{kHz}$, and at the $p<0.05$ level for 11.3, 16, and 45.2 $\mathrm{kHz}$. All data are normalized to the mean values for each group at 8 weeks. 0 C Lesion group is defined as shown in Figure $3 A$. Group sizes are as described in Figure 3.

To quantify the degree of de-efferentation, we measured VAT-positive terminals in the inner and outer hair cell areas in image stacks from 8 cochlear regions from each case. Since the extent of de-efferentation, in a given case, sometimes varied along the cochlear spiral, we binned the 8 measures from each case into 3 cochlear regions: apical $(5.6-8.0 \mathrm{kHz})$, middle $(11.3-32 \mathrm{kHz})$, and basal $(45.2-64 \mathrm{kHz})$. Plotting the results for each region from each case (Fig. $3 A$ ) shows the variable degrees of MOC and LOC degeneration. We defined OC Lesion as those cochlear regions with at least $25 \%$ loss of both LOC and MOC terminals, with respect to the mean values from young control ears. This criterion clearly separates the OC Lesion group from all control ears (Fig. 3A). Among the OC Lesion cases, the mean LOC and MOC losses (Fig. $3 B$ ) were slightly more complete in the apical half of the cochlea $(\sim 35 \%$ survival $)$ than in the basal half $(\sim 50 \%$ survival). The MOC survival was bilaterally symmetrical in the midline-cut cases, with interaural differences always $<6 \%$ (data not shown). The effects of aging alone (in control ears) on the density of cochlear efferent innervation were minimal at 45 weeks of age (Fig. 3B).

\section{Assessing cochlear de-efferentation via MOC- mediated suppression}

When the MOC fibers are activated, either by sound or artificially by electrical stimulation, cochlear responses are suppressed (Gui- nan, 1996). This MOC-mediated suppression arises because activation of the nicotinic acetylcholine receptors on outer hair cells elicits a signaling cascade that ultimately reduces the outer hair cells' contributions to cochlear mechanical amplification. Because sound-evoked MOC activity is greatly reduced in anesthetized mice (Chambers et al., 2012), we activated the MOC system by shocking their axons at the floor of the IV ${ }^{\text {th }}$ ventricle (Fig. 2A). Since the LOC axons are unmyelinated, the LOC system is not activated by these shock trains (Gifford and Guinan, 1987).

To assay for MOC-mediated cochlear suppression, we measure the amplitude of cochlear responses to low-level acoustic stimulation before, during, and after a $70 \mathrm{~s}$ train of 200/s shocks delivered to the MOC fibers (Fig. 3C). The cochlear response we choose to measure is the amplitude of the DPOAE, because it is driven by the outer hair cell amplifier and because it can be measured easily in the ear-canal sound pressure. The immediate DPOAE suppression at the onset of the shock train (Fig. 3C, inset) provides a robust measure of the MOC effect.

In normal ears, the magnitude of MOC suppression varies with cochlear region, with the maximum effect seen at frequencies near 16-22 kHz (Fig. 3C), where the density of MOC innervation is greatest in mice (Maison et al., 2003). In OC Lesion regions, where the mean survival of MOC terminals ranged from $\sim 30$ to $60 \%$ (Fig. $3 B)$, the mean MOC effect was also significantly reduced (Fig. $3 C$ ). For each of the stimulus frequencies tested, there was a clear correlation between the extent of MOC terminal loss in the appropriate cochlear location and the reduction in size of the MOC effect: data for the $22.6 \mathrm{kHz}$ region are shown in Figure $3 D(r=0.76)$. The data suggest that our histological measure of cochlear de-efferentation provides a reasonable metric of the loss of cochlear gain control.

\section{Assessing age-related cochlear dysfunction}

All animals were housed throughout the 39-week duration of the experiment in an animal care facility, where the ambient sound pressure was $40 \mathrm{~dB}$ SPL, except for brief periods during cage cleaning when peak levels reached $70 \mathrm{~dB}$ SPL (Fig. 1). For reference, $40 \mathrm{~dB}$ SPL is approximately the level in a quiet library, and $70 \mathrm{~dB}$ SPL is well below that measured in a busy restaurant.

To monitor age-related effects on cochlear function, and to differentiate presynaptic from postsynaptic dysfunction in the auditory periphery, we measured DPOAEs and ABRs as animals aged to 45 weeks, which corresponds to $\sim 30 \%$ of their average (2.75 years) lifespan (Sergeyenko et al., 2013). DPOAEs are sounds created within the normal cochlea that can be measured from the ear canal with a sensitive microphone. Normal DPOAEs require normal outer hair cell function (Liberman et al., 2004), but are unaffected by degeneration of cochlear nerve fibers, which synapse, almost exclusively, with the inner hair cells (Fig. 
$2 B)$. Wave 1 of the ABR reflects the synchronous sound-evoked activity in the cochlear nerve. Thus, ABR amplitude reductions in the presence of normal DPOAEs are a sign of cochlear neuropathy (Mills, 2003).

We measured cochlear function at six log-spaced time intervals from 8 weeks to 45 weeks of age. The age-related threshold elevation in the Control ears was minimal, whether measured by DPOAEs or ABRs: $<5 \mathrm{~dB}$ when averaged across all test frequencies (Fig. $4 A, B$ ) and $<10 \mathrm{~dB}$ even at high frequencies, where age-related hearing loss tends to be worse (Fig. 4C,D). In contrast, in the OC Lesion group, threshold shift at 45 weeks had grown to almost $30 \mathrm{~dB}$, when measured by ABRs (Fig. 4B). The significantly smaller age-related shift in DPOAE thresholds, only $\sim 10 \mathrm{~dB}$ at 45 weeks (Fig. 4A), suggests that only a fraction of this age-related change is attributable to outer hair cell dysfunction.

Prior work on cochlear neuropathy after acoustic overexposure has shown that ABR thresholds are less sensitive metrics of primary neural degeneration than the suprathreshold amplitudes of ABR Wave 1 , the summed contributions of the cochlear nerve (Melcher et al., 1996). This is largely because the neural loss is, at least initially, selective for those cochlear nerve fibers with high thresholds (Furman et al., 2013), which make minimal contributions to the threshold determination but contribute to the growth of response amplitude with increasing sound pressure level. In the present study, the OC Lesion group showed a dramatic decrease in the Wave 1 suprathreshold response amplitudes at all frequency regions (Fig. 5D). The ABR amplitude decrements were much larger than the reduction in DPOAE response amplitudes (Fig. $5 C$ ). This is especially clear at low frequencies, where the DPOAE changes were minimal (Fig. $5 \mathrm{C}$ ). However, even at $22.6 \mathrm{kHz}$, the $10 \mathrm{~dB}$ DPOAE reduction in the OC Lesion group at 45 weeks (Fig. $5 C$ ) translates into an $8 \mathrm{~dB}$ reduction in stimulus level (based on mean amplitude-vs-level data from age-matched controls; data not shown), whereas the $70 \%$ reduction in mean ABR Wave 1 amplitude (Fig. 5D) translates into a $31 \mathrm{~dB}$ stimulus attenuation (based on mean ABR amplitude-vs-level data in age-matched controls; data not shown). These data are consistent with a loss of responsive cochlear nerve terminals in the de-efferented ears.

\section{Assessing age-related cochlear neuropathy}

To quantify cochlear-nerve synapses, we used immunomarkers for presynaptic and postsynaptic proteins. At each synapse (Fig. $2 B)$, a presynaptic ribbon, an electron-dense body within the inner hair cell, is surrounded by synaptic vesicles and opposes a single postsynaptic density on the terminal bouton of a cochlearnerve fiber (Liberman, 1980; Khimich et al., 2005), which expresses AMPA-type glutamate receptors (Matsubara et al., 1996). When the organ of Corti is immunostained with antibodies to
DPOAES
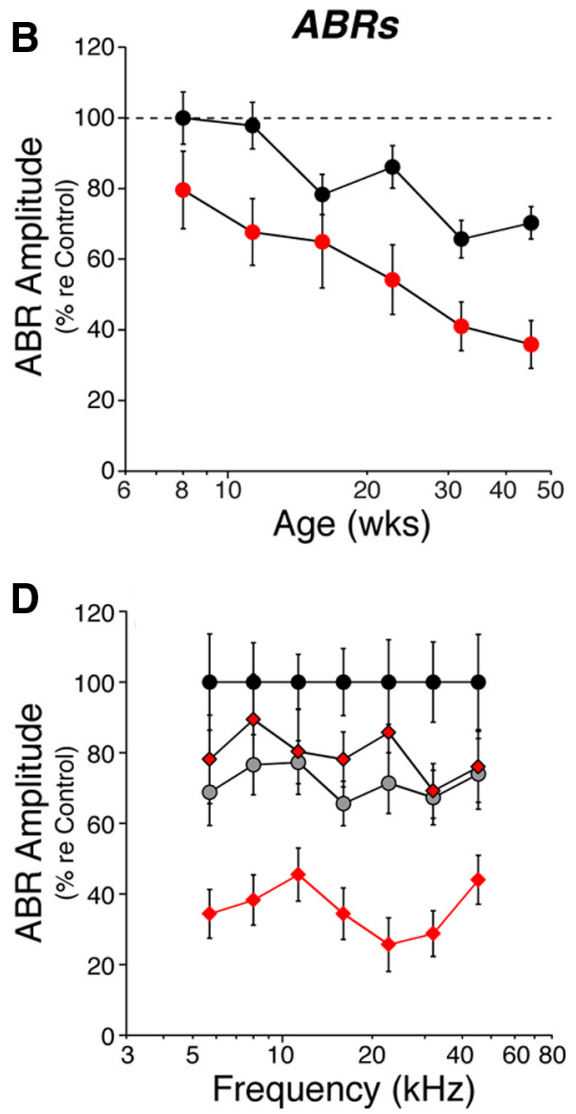

Figure 5. Age-related decrements in cochlear response amplitudes were more pronounced in de-efferented regions, especially as measured via $A B R$ s. Suprathreshold response amplitudes vs age $(\boldsymbol{A}, \boldsymbol{B})$ or frequency $(\boldsymbol{C}, \boldsymbol{D})$ for each group as seen via $\mathrm{DPOAEs}(\boldsymbol{A}$, $C$ or $A B R s(B, D)$. For each measure, responses at $60-80 \mathrm{~dB}$ SPL were averaged and normalized with respect to the mean values

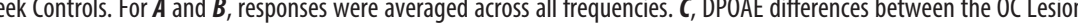
sidered. OC Lesion group is defined as described in Figure 3A. Group sizes are as described in Figure 3. All data are group means

CtBP2 (a component of the synaptic ribbon; Schmitz et al., 2000) and GluA2 (a glutamate receptor subunit), each cochlear-nerve synapse is seen as a pair of immunopositive puncta (Fig. 2E, inset). In a young normal ear, each inner hair cell has 10-20 synapses arrayed around its basolateral membrane (Fig. 2E), depending on cochlear location (Kujawa and Liberman, 2009).

In a middle-aged ( 45 week) Control ear, the number of synapses was modestly reduced (Fig. 6B), i.e., by $2-20 \%$ depending on cochlear location. This degree of age-related cochlear neuropathy is consistent with a recent report (Sergeyenko et al., 2013). In middle-aged ears without efferent feedback, the neuropathy increased dramatically, as seen by the confocal image in Figure $2 F$. Synaptic counts revealed that the synaptic loss varied from 30 to $60 \%$ loss depending on location (Fig. 6B). There was no loss of inner or outer hair cells in the middle-aged (45 weeks) Control ears, and hair cell losses in the OC Lesion group were minimal and seen only among outer hair cells and only at the most basal locus (Fig. 6A).

To determine whether the synaptic degeneration was more closely linked to loss of the MOC or the LOC innervation, we separately considered the correlations in each frequency region. One such comparison, i.e., the correlation between LOC survival and cochlear-nerve synapse survival in the $22.6 \mathrm{kHz}$ region, is 

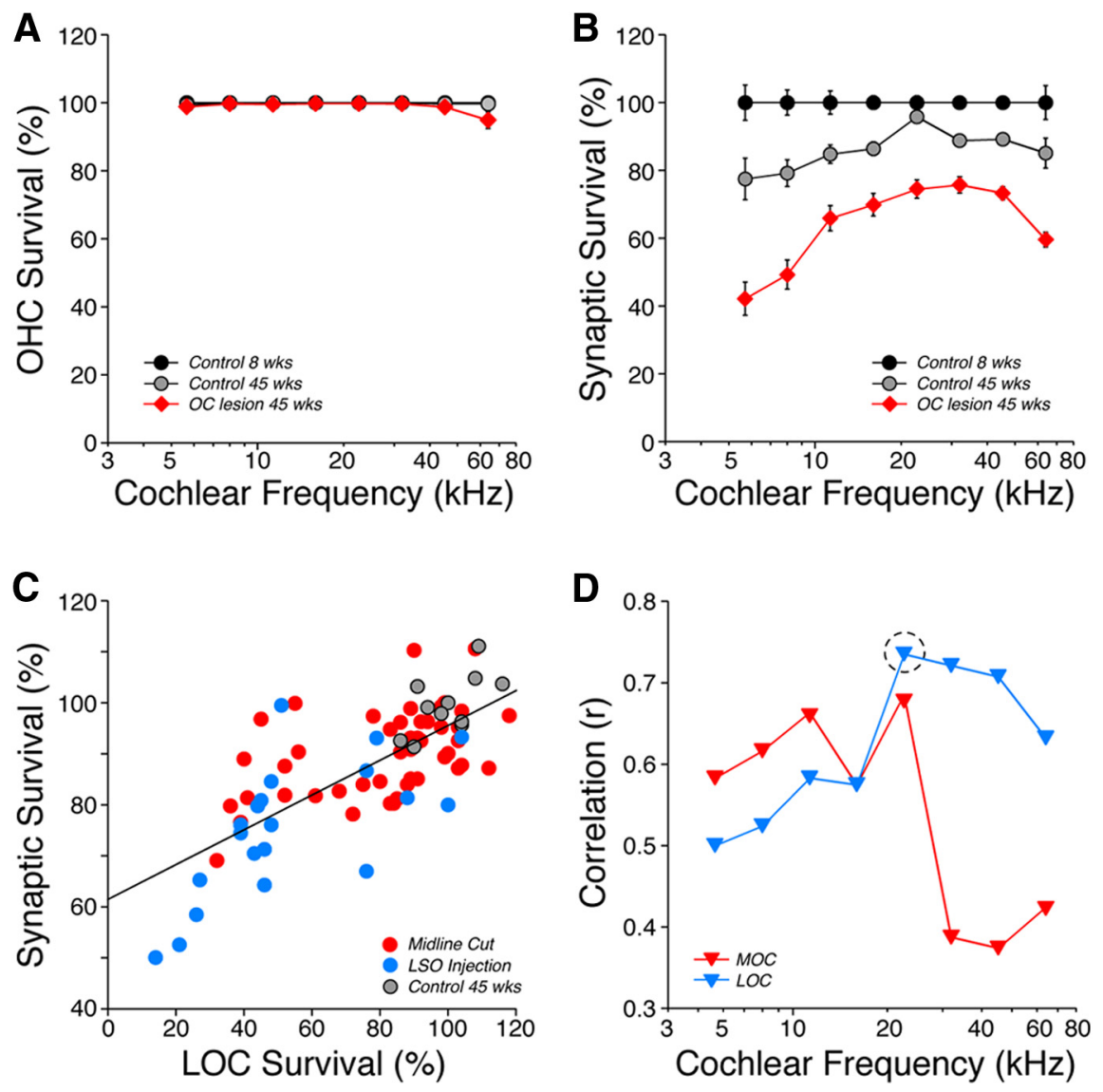

Figure 6. Age-related loss of afferent synapses was increased in de-efferented ears, and both LOC and MOC systems appear to contribute to survival. $\boldsymbol{A}$, Mean outer hair cell (OHC) loss ( \pm SEMs) at 45 weeks in control and de-efferented groups. $\boldsymbol{B}$, Mean counts of afferent synapses in the inner hair cell (IHC) area ( \pm SEMs), normalized to the values in young (8 week) control ears to estimate percentage survival. OC Lesion group in $\boldsymbol{A}$ and $\boldsymbol{B}$ is defined as shown in Figure $2 A$. The differences in synaptic survival between the $O C$ Lesion group and age-matched controls was highly significant $(p \ll 0.01)$ at all frequency regions. $C$, The correlation, in the 22 $\mathrm{kHz}$ region at 45 weeks, between $L O C$ survival (from Fig. $2 A$ ) and cochlear-nerve synapse survival. Each point is from a different ear; the best-fit straight line is shown $(r=0.73)$. Data are included from controls and all ears targeted by 0 C surgery $(n=42)$; i.e., both ears after midline cuts and the ipsilateral ear after LSO lesions (Fig. 3A). D, Correlation coefficients, as a function of cochlear frequency, between cochlear-nerve synaptic loss and either MOC or LOC survival. The dashed circle shows the value derived from the data in $\boldsymbol{C}$.

illustrated in Figure $6 C$ : the correlation coefficient for these data was 0.73 . The correlation coefficients arising from analogous plots at all 8 cochlear regions evaluated are compared for MOC and LOC survival in Figure 6D; in the apical half of the cochlea, MOC projections appear slightly better correlated with synaptic survival, whereas in the basal half of the cochlea, the LOC contributions clearly dominate.

\section{Discussion}

OC feedback: the search for a functional role

Activity in the MOC pathway, elicited by sound or by shocking the OC bundle, suppresses cochlear responses by turning down the gain of the outer-hair-cell "amplifier," which decreases sound-induced cochlear motion (Guinan, 2006). Effects of LOC neurons are more poorly understood, because their axons are unmyelinated. We do not know whether they respond to sound; however, indirect evidence suggests they can modulate cochlearnerve excitability (Groff and Liberman, 2003). The functional role of these OC systems remains controversial.

Animal studies suggest they may (1) mediate selective attention by suppressing auditory responses when performing a visual task (Delano et al., 2007), (2) improve discrimination of complex stimuli in a noisy background (Dewson, 1968) by suppressing response to continuous noise and decreasing cochlear-nerve adaptation (Kawase et al., 1993), (3) mediate the relearning of a sound-localization task after monaural ear-plugging (Irving et al., 2011) by altering the binaural balance of excitability in the two cochlear nerves (Darrow et al., 2006), or (4) suppress responses to selfgenerated signals, e.g., in fish during swimming (Highstein, 1992).

Human studies suggest that loss of OC feedback (Chays et al., 2002) has minimal effects on intensity discrimination, frequency selectivity, loudness adaptation, or frequency discrimination, but decreases performance on tasks requiring selective attention in the frequency domain (Scharf et al., 1997). Human studies also suggest that intersubject variability in OC reflex strength, which can be assessed by measuring suppression of ipsilateral DPOAEs by contralateral noise (Collet et al., 1990), correlates with performance on discrimination of signals in noise (Micheyl and Collet, 1996).

Many ideas about OC function have been pursued, because most effects of deefferentation are small. Although cochlear de-efferentation can dramatically increase noise-induced permanent threshold shifts (Kujawa and Liberman, 1997), the sound pressures required to produce such shifts are high, e.g., 105-110 dB SPL for $2 \mathrm{~h}(\mathrm{Ra}-$ jan and Johnstone, 1989; Robertson and Anderson, 1994; Reiter and Liberman, 1995; Kujawa and Liberman, 1997; Maison et al., 2002). Thus, OC-mediated protection may be an epiphenomenon (Christopher Kirk and Smith, 2003): i.e., important in industrialized society where intense noise is rampant, but unlikely to represent the selective pressure explaining the evolution of this feedback system.

\section{OC feedback and age-related hearing loss}

The discovery that moderate levels of noise (e.g., $100 \mathrm{~dB}$ SPL for $2 \mathrm{~h}$ ), which produce only temporary threshold elevation and no hair cell damage, can permanently destroy cochlear afferent synapses (Kujawa and Liberman, 2009) suggested that a reexamination of OC-mediated protection was warranted, focusing on cochlear neuropathy and attenuation of suprathreshold responses rather than on hair cell damage and associated threshold elevations. Having demonstrated that de-efferentation exacerbated cochlear neuropathy from exposures even at moderate sound pressures (84 dB SPL for 1 week; Maison et al., 2013), in the present study we avoided acoustic overexposure altogether to ask whether efferent-mediated protection is necessary simply to maintain normal synaptic function in the aging ear.

Cochlear synaptic loss in aging mice with normal efferent function progresses monotonically from weaning (4 weeks) to death ( $\sim 2.75$ years), followed, after a few months, by a proportional loss of the neuronal cell bodies (Sergeyenko et al., 2013). 
Here, we show (Fig. 6B) that loss of efferent feedback has transformed a middle-aged ear ( $\sim 15 \%$ synaptic loss at 45 weeks) to a senescent ear: synaptic loss in de-efferented ears ( $\sim 40 \%$ across all locations) corresponds to values in the oldest survivors (144 weeks) from the prior study (Sergeyenko et al., 2013).

To whatever extent the environment is noisier than in the present study (Fig. 1), or the de-efferentation more complete than in the present study ( $\sim 50 \%$ survival; Fig. $3 B$ ), or the postde-efferentation longer than that in the present study (39 weeks), the age-related neural degeneration will presumably be even more pronounced. Without efferent feedback, damage to outer hair cells also increases, which elevates hearing thresholds (Fig. 4), and loss of cochlear nerve synapses (Fig. 6) likely causes problems hearing in a noisy environment. These impairments are the two classic signs of age-related hearing loss in humans. Since MOC reflex strength varies among animals (Maison and Liberman, 2000) and humans (Backus and Guinan, 2007), and can be assessed noninvasively (Collet et al., 1990), a test of efferent reflex strength might identify those most at risk for acquiring significant age-related hearing impairment.

\section{MOC versus LOC contributions and mechanisms}

The synapse between inner hair cells and cochlear nerve fibers is exceptionally active. Even in the absence of sound, $60 \%$ of fibers discharge spontaneously at 20-120 spikes/s (Liberman, 1978). At $30-40 \mathrm{~dB}$ above threshold, almost all cochlear neurons will discharge at 200 spikes/s for as long as the stimulus is present (Liberman, 1978). When the ear is stimulated by high-level noise (e.g., $100 \mathrm{~dB}$ above threshold for tens of minutes), cochlear neuropathy is seen immediately postexposure as an acute swelling of the cochlear nerve terminals near their synapses with inner hair cells (Robertson, 1983). This swelling can be blocked by glutamate antagonists (Pujol and Puel, 1999) and mimicked by glutamate agonists in the absence of sound (Pujol et al., 1993), suggesting a type of glutamate excitotoxicity at this highly active synapse.

Although efferent lesions in the present study involved both LOC and MOC subsystems, our analysis (Fig. 6) suggested that MOC effects are most important to efferent-mediated protection in the apical half of the cochlea, whereas LOC contributions dominate in the basal half. Given the different central origins and peripheral targets of the two efferent subsystems (Fig. $2 A, B$ ), the mechanisms underlying their protective effects are likely different. The LOC system has been implicated in the control of excitotoxicity via its direct dopaminergic effects on the postsynaptic cochlear-nerve terminal (Ruel et al., 2001); however, the mechanisms underlying this putative protective effect have not been investigated.

The MOC system could minimize damage by feedback gaincontrol: as sound pressure increases, increasing MOC activation decreases sound-evoked vibrations of the sensory epithelium (Murugasu and Russell, 1996) and thereby decreases discharge rate in cochlear nerve fibers (Stankovic and Guinan, 1999). Interestingly, the largest effects of MOC feedback are on highthreshold fibers, which are also most vulnerable to acoustic overexposure (Furman et al., 2013), Furthermore, for those highthreshold fibers, the biggest MOC-mediated rate suppression is for moderate-level sounds (Guinan and Stankovic, 1996) comparable to the peak levels in our animal care facility (Fig. 1) and very common in everyday life. If age-related synaptopathy is proportional to the average sound-evoked discharge rate in the cochlear nerve, sound-evoked feedback via an intact MOC reflex should reduce neural degeneration over the course of a lifetime. Since the MOC reflex is driven by sound-evoked activity in the cochlear nerve, there may be a vicious cycle in the aging ear, in which diminished efferent function causes cochlear-nerve loss, which further decreases sound-evoked efferent activation, which exacerbates the neuronal loss.

\section{References}

Backus BC, Guinan JJ Jr (2007) Measurement of the distribution of medial olivocochlear acoustic reflex strengths across normal-hearing individuals via otoacoustic emissions. J Assoc Res Otolaryngol 8:484-496. CrossRef Medline

Bohne BA, Rabbitt KD (1983) Holes in the reticular lamina after noise exposure: implication for continuing damage in the organ of Corti. Hear Res 11:41-53. CrossRef Medline

Brown MC (1993) Fiber pathways and branching patterns of biocytinlabeled olivocochlear neurons in the mouse brainstem. J Comp Neurol 337:600-613. CrossRef Medline

Chambers AR, Hancock KE, Maison SF, Liberman MC, Polley DB (2012) Sound-evoked olivocochlear activation in unanesthetized mice. J Assoc Res Otolaryngol 13:209-217. CrossRef Medline

Chays A, Magnan J, Maison S (2002) Absence d'efférences olivocochléaires dans les prélèvements de nerf vestibulaire du patient neurotomisé. JFORL 51:145-150.

Christopher Kirk E, Smith DW (2003) Protection from acoustic trauma is not a primary function of the medial olivocochlear efferent system. J Assoc Res Otolaryngol 4:445-465. CrossRef Medline

Collet L, Kemp DT, Veuillet E, Duclaux R, Moulin A, Morgon A (1990) Effect of contralateral auditory stimuli on active cochlear micromechanical properties in human subjects. Hear Res 43:251-261. CrossRef Medline

Costalupes JA, Young ED, Gibson DJ (1984) Effects of continuous noise backgrounds on rate response of auditory nerve fibers in cat. J Neurophysiol 51:1326-1344. Medline

Darrow KN, Maison SF, Liberman MC (2006) Cochlear efferent feedback balances interaural sensitivity. Nat Neurosci 9:1474-1476. CrossRef Medline

Delano PH, Elgueda D, Hamame CM, Robles L (2007) Selective attention to visual stimuli reduces cochlear sensitivity in chinchillas. J Neurosci 27 4146-4153. CrossRef Medline

Dewson JH 3rd (1968) Efferent olivocochlear bundle: some relationships to stimulus discrimination in noise. J Neurophysiol 31:122-130. Medline

Dubno JR, Dirks DD, Morgan DE (1984) Effects of age and mild hearing loss on speech recognition in noise. J Acoust Soc Am 76:87-96. CrossRef Medline

Furman AC, Kujawa SG, Liberman MC (2013) Noise-induced cochlear neuropathy is selective for fibers with low spontaneous rates. J Neurophysiol 110:577-586. CrossRef Medline

Gifford ML, Guinan JJ Jr (1987) Effects of electrical stimulation of medial olivocochlear neurons on ipsilateral and contralateral cochlear responses. Hear Res 29:179-194. CrossRef Medline

Groff JA, Liberman MC (2003) Modulation of cochlear afferent response by the lateral olivocochlear system: activation via electrical stimulation of the inferior colliculus. J Neurophysiol 90:3178-3200. CrossRef Medline

Guinan JJ Jr (1996) Physiology of olivocochlear efferents. In: The cochlea (Dallos P, Popper AN, Fay RR, eds), pp 435-502. New York: Springer.

Guinan JJ Jr (2006) Olivocochlear efferents: anatomy, physiology, function, and the measurement of efferent effects in humans. Ear Hear 27:589-607. CrossRef Medline

Guinan JJ Jr, Stankovic KM (1996) Medial efferent inhibition produces the largest equivalent attenuations at moderate to high sound levels in cat auditory-nerve fibers. J Acoust Soc Am 100:1680-1690. CrossRef Medline

Highstein SM (1992) The efferent control of the organs of balance and equilibrium in the toadfish, Opsanus tau. Ann N Y Acad Sci 656:108-123. CrossRef

Irving S, Moore DR, Liberman MC, Sumner CJ (2011) Olivocochlear efferent control in sound localization and experience-dependent learning. J Neurosci 31:2493-2501. CrossRef Medline

Kawase T, Delgutte B, Liberman MC (1993) Antimasking effects of the olivocochlear reflex. II. Enhancement of auditory-nerve response to masked tones. J Neurophysiol 70:2533-2549. Medline

Khimich D, Nouvian R, Pujol R, Tom Dieck S, Egner A, Gundelfinger ED, 
Moser T (2005) Hair cell synaptic ribbons are essential for synchronous auditory signaling. Nature 434:889-894. CrossRef Medline

Kujawa SG, Liberman MC (1997) Conditioning-related protection from acoustic injury: effects of chronic de-efferentation and sham surgery. J Neurophysiol 78:3095-3106. Medline

Kujawa SG, Liberman MC (2009) Adding insult to injury: cochlear nerve degeneration after "temporary" noise-induced hearing loss. J Neurosci 29:14077-14085. CrossRef Medline

Liberman LD, Wang H, Liberman MC (2011) Opposing gradients of ribbon size and AMPA receptor expression underlie sensitivity differences among cochlear-nerve/hair-cell synapses. J Neurosci 31:801-808. CrossRef Medline

Liberman MC (1978) Auditory-nerve response from cats raised in a lownoise chamber. J Acoust Soc Am 63:442-455. CrossRef Medline

Liberman MC (1980) Morphological differences among radial afferent fibers in the cat cochlea: An electron-microscopic study of serial sections. Hear Res 3:45-63. CrossRef Medline

Liberman MC, Dodds LW (1984) Single-neuron labeling and chronic cochlear pathology. III. Stereocilia damage and alterations of threshold tuning curves. Hear Res 16:55-74. CrossRef Medline

Liberman MC, Kiang NY (1978) Acoustic trauma in cats. Cochlear pathology and auditory-nerve activity. Acta Otolaryngol Suppl 358:1-63. Medline

Liberman MC, Zuo J, Guinan JJ Jr (2004) Otoacoustic emissions without somatic motility: can stereocilia mechanisms drive the mammalian cochlea? J Acoust Soc Am 116:1649-1655. CrossRef Medline

Maison SF, Liberman MC (2000) Predicting vulnerability to acoustic injury with a noninvasive assay of olivocochlear reflex strength. J Neurosci 20: 4701-4707. Medline

Maison SF, Luebke AE, Liberman MC, Zuo J (2002) Efferent protection from acoustic injury is mediated via alpha9 nicotinic acetylcholine receptors on outer hair cells. J Neurosci 22:10838-10846. Medline

Maison SF, Adams JC, Liberman MC (2003) Olivocochlear innervation in the mouse: immunocytochemical maps, crossed versus uncrossed contributions, and transmitter colocalization. J Comp Neurol 455:406-416. CrossRef Medline

Maison SF, Vetter DE, Liberman MC (2007) A novel effect of cochlear efferents: in vivo response enhancement does not require alpha9 cholinergic receptors. J Neurophysiol 97:3269-3278. CrossRef Medline

Maison SF, Usubuchi H, Liberman MC (2013) Efferent feedback minimizes cochlear neuropathy from moderate noise exposure. J Neurosci 33:55425552. CrossRef Medline

Makary CA, Shin J, Kujawa SG, Liberman MC, Merchant SN (2011) Agerelated primary cochlear neuronal degeneration in human temporal bones. J Assoc Res Otolaryngol 12:711-717. CrossRef Medline

Matsubara A, Laake JH, Davanger S, Usami S, Ottersen OP (1996) Organization of AMPA receptor subunits at a glutamate synapse: a quantitative immunogold analysis of hair cell synapses in the rat organ of Corti. J Neurosci 16:4457-4467. Medline

Melcher JR, Guinan JJ Jr, Knudson IM, Kiang NY (1996) Generators of the brainstem auditory evoked potential in cat. II. Correlating lesion sites with waveform changes. Hear Res 93:28-51. CrossRef Medline

Micheyl C, Collet L (1996) Involvement of the olivocochlear bundle in the detection of tones in noise. J Acoust Soc Am 99:1604-1610. CrossRef Medline

Mills DM (2003) Differential responses to acoustic damage and furosemide in auditory brainstem and otoacoustic emission measures. J Acoust Soc Am 113:914-924. CrossRef Medline
Murugasu E, Russell IJ (1996) The effect of efferent stimulation on basilar membrane displacement in the basal turn of the guinea pig cochlea. J Neurosci 16:325-332. Medline

Osen KK, Roth K (1969) Histochemical localization of cholinesterases in the cochlear nuclei of the cat, with notes on the origin of acetylcholinesterase-positive afferents and the superior olive. Brain Res 16:165-185. CrossRef Medline

Pujol R, Puel JL (1999) Excitotoxicity, synaptic repair, and functional recovery in the mammalian cochlea: a review of recent findings. Ann NY Acad Sci 884:249-254. CrossRef Medline

Pujol R, Puel JL, Gervais d'Aldin C, Eybalin M (1993) Pathophysiology of the glutamatergic synapses in the cochlea. Acta Otolaryngol 113:330-334. CrossRef Medline

Rajan R (1988) Effect of electrical stimulation of the crossed olivocochlear bundle on temporary threshold shifts in auditory sensitivity. I. Dependence on electrical stimulation parameters. J Neurophysiol 60:549-568. Medline

Rajan R, Johnstone BM (1989) Contralateral cochlear destruction mediates protection from monoaural loud sound exposures through the crossed olivocochlear bundle. Hear Res 39:263-277. CrossRef Medline

Reiter ER, Liberman MC (1995) Efferent-mediated protection from acoustic overexposure: relation to slow effects of olivocochlear stimulation. J Neurophysiol 73:506-514. Medline

Robertson D (1983) Functional significance of dendritic swelling after loud sounds in the guinea pig cochlea. Hear Res 9:263-278. CrossRef Medline

Robertson D, Anderson CJ (1994) Acute and chronic effects of unilateral elimination of auditory nerve activity on susceptibility to temporary deafness induced by loud sound in the guinea pig. Brain Res 646:37-43. CrossRef Medline

Robertson D, Johnstone BM, McGill TJ (1980) Effects of loud tones on the inner ear: a combined electrophysiological and ultrastructural study. Hear Res 2:39-43. CrossRef Medline

Rubel EW, Furrer SA, Stone JS (2013) A brief history of hair cell regeneration research and speculations on the future. Hear Res 297:42-51. CrossRef Medline

Ruel J, Nouvian R, Gervais d'Aldin C, Pujol R, Eybalin M, Puel JL (2001) Dopamine inhibition of auditory nerve activity in the adult mammalian cochlea. Eur J Neurosci 14:977-986. CrossRef Medline

Schaette R, McAlpine D (2011) Tinnitus with a normal audiogram: physiological evidence for hidden hearing loss and computational model. J Neurosci 31:13452-13457. CrossRef Medline

Scharf B, Magnan J, Chays A (1997) On the role of the olivocochlear bundle in hearing: 16 case studies. Hear Res 103:101-122. CrossRef Medline

Schmitz F, Königstorfer A, Südhof TC (2000) A component of synaptic ribbons: a protein's journey through evolution provides insight into synaptic ribbon function. Neuron 28:857-872. CrossRef Medline

Sergeyenko Y, Lall K, Liberman MC, Kujawa SG (2013) Age-related synaptopathy: an early-onset contributor to auditory functional decline. J Neurosci 33:13686-13694. CrossRef Medline

Stankovic KM, Guinan JJ Jr (1999) Medial efferent effects on auditorynerve responses to tail-frequency tones. I. Rate reduction. J Acoust Soc Am 106:857-869. CrossRef Medline

Taberner AM, Liberman MC (2005) Response properties of single auditory nerve fibers in the mouse. J Neurophysiol 93:557-569. Medline

Wiederhold ML, Kiang NY (1970) Effects of electric stimulation of the crossed olivocochlear bundle on single auditory-nerve fibers in the cat. J Acoust Soc Am 48:950-965. CrossRef Medline 